Cittadini et al. Phenolic effects on brain

\title{
Effects of Bioavailable Phenolic Compounds from Ilex paraguariensis on the Brain of Mice with Lung Adenocarcinoma
}

\section{María C. Cittadini' ${ }^{1}$, Gastón Repossi ${ }^{1,2}$, Claudia Albrecht ${ }^{1,3}$, Romina Di Paola Naranjo ${ }^{4-6}$, Agustín R. Miranda ${ }^{1,7}$, Sonia de Pascual-Teresa ${ }^{8}$, Elio A. Soria ${ }^{1,2 *}$}

1. Consejo Nacional de Investigaciones Científicas y Técnicas, CONICET, INICSA. Enrique Barros, Ciudad Universitaria, Córdoba 5014, Argentina.

2. Universidad Nacional de Córdoba, Facultad de Ciencias Médicas, Cátedra de Biología Celular, Histología y Embriología, Instituto de Biología Celular. Enrique Barros, Ciudad Universitaria, Córdoba 5014, Argentina.

3. Universidad Nacional de Córdoba, Facultad de Ciencias Médicas, Escuela de Nutrición, CENINH. Enrique Barros, Ciudad Universitaria, Córdoba 5014, Argentina.

4. Universidad Nacional de Córdoba, Facultad de Ciencias Químicas. Maestro López, Ciudad Universitaria, Córdoba 5014, Argentina.

5. Universidad Nacional de Córdoba, Secretaría de Ciencia y Tecnología, ISIDSA. Juan Filloy, Ciudad Universitaria, Córdoba 5014, Argentina.

6. Consejo Nacional de Investigaciones Científicas y Técnicas, CONICET, ICYTAC. Juan Filloy, Ciudad Universitaria, Córdoba 5014, Argentina.

7. Universidad Nacional de Córdoba, Facultad de Ciencias Médicas, Escuela de Fonoaudiología. Enrique Barros, Ciudad Universitaria, Córdoba 5014, Argentina.

8. Consejo Superior de Investigaciones Científicas, CSIC, ICTAN. José Antonio Novais 10, Madrid 28040, Spain.

*Corresponding author: E-mail: easoria@fcm.unc.edu.ar. Address: INICSA, Enrique Barros, Ciudad Universitaria, Córdoba 5014, Argentina. Telephone/Fax: +543514334020. 
Cittadini et al. Phenolic effects on brain

\begin{abstract}
Lung carcinoma is one of the most common cancers and has a high mortality. Recently, we showed that it produces neurological paraneoplastic syndrome, with Ilex paraguariensis extract (IP) exerting palliative effects due to its content of phenolic compounds. It is possible, therefore, that these diet agents can arrive at the brain and exert neuroprotection, after the oral intake of IP. Here, the aim was to investigate the protective role of bioavailable IP compounds on the telencephalon and diencephalon in lung adenocarcinoma-bearing BALB/cJ males. Mice aged 2months were treated for 3 weeks with 0-100 IP mg/Kg/day. HPLC-UV revealed the presence of chlorogenic acid and quercetin in brain regions, liver and tumour, in an IP dose-dependent manner. Brain was also evaluated histologically, and IL-6 was measured by ELISA. Chlorogenic acid was the major compound found in brain, whereas quercetin was observed at the diencephalon to a lesser extent. Both compounds were involved in IP dose-dependent diencephalic interleukin-6 reduction. Histology suggested cellular protection with less apoptosis in chlorogenic-exposed areas. Taken together, chlorogenic acid and quercetin from dietary IP were bioavailable and bioactive in brain, thereby attenuating lung cancer-related neuroinflammation and damage. These findings support plant-based strategies to improve prognosis.
\end{abstract}

\title{
Keywords
}

Chlorogenic acid; High performance liquid chromatography; Interleukin 6; Paraneoplastic syndrome; Quercetin. 
Cittadini et al. Phenolic effects on brain

\section{Introduction}

Lung cancer is worldwide one of the most frequent and lethal human neoplasias. This tumour affects the central nervous system (CNS) directly by metastasis, and indirectly by paraneoplastic syndromes (Jurado Gámez et al, 2001; Giglio et al, 2010; Koike et al, 2015). Moreover, it has been shown to induce highly deteriorating neuroinflammation and brain damage at the early onset of the condition in several patients (Islami and Sobue, 2015; Sateia et al, 2017). Although primary prevention of this illness is through tabaquism control, there are few preventive resources available to avoid or at least delay its progression and complications, which is known as secondary and tertiary prevention.

Plants are sources of a myriad of bioactive compounds, which can be incorporated into the human diet to exert chemoprevention of neurological complications (Miranda et al, 2017). Polyphenols, which are found in most plants, are phytochemicals that exert systemic immunomodulation and cytoprotection by multitarget mechanisms, such as regulation of the redox status and biological pathways, thereby improving human health (Miranda et al, 2017; Cittadini et al, 2018). Thus, they have potential as cancer chemopreventive and neuroprotective agents.

Ilex paraguariensis A. St.-Hil. (Aquifoliaceae) (IP) is a South American plant widely consumed as a tea, known as "yerba mate" or "mate" in the Spanish language, with dietary use and availability growing around the world (Bracesco et al, 2011). This plant and its derivatives, such as tea and its extract, are enriched in bioactive compounds which reach the CNS and induce desired effects (Miranda et al, 2017; Cittadini et al, 2018; Bracesco et al, 2011; Orosz, 2018; Albrecht et al, 2017). The IP extract mainly contains phenolic compounds, such as quinic acid, 3caffeoylquinic acid, chlorogenic acid (the major compound), 4-caffeoylquinic acid, 1- 
Cittadini et al. Phenolic effects on brain

caffeoylquinic acid, caffeoyl acid glucose, quercetin rutinoside, and isorhamnetin rutinoside, among others (Cittadini et al, 2018; Bracesco et al, 2011).

Although the capacity of phenolic compounds to cross the blood-brain barrier has been reported (Andrade and Assuncao, 2012; Cittadini et al, 2015), experimental designs often apply pure molecules by unusual ways of administration (El Mohsen et al, 2002; Ishisaka et al, 2011). Thus, it is necessary to have a better understanding of how these compounds affect the organism based on more common conditions, such as diet supply. Consequently, we carried out a preclinical study using lung adenocarcinoma (LAC-1)-bearing male BALB/cJ mice, which is an excellent model to investigate cancer evolution and neuroprotective effects of these compounds on the brain (Piegari et al, 2017).

\section{Materials and Methods}

\section{Extract preparation}

I. paraguariensis A. St.-Hil. (Aquifoliaceae) was obtained from commercial agroecological culture (Jactancia, Argentina), and prepared as a tea: $1 \mathrm{~g}$ of pulverised air-dried sample was extracted by adding $10 \mathrm{~mL}$ of $83^{\circ} \mathrm{C}$ water, which was left to cool to room temperature for $1 \mathrm{~h}$ under constant agitation. After this, the blend was centrifuged, and the extract was recovered from the supernatant by filtration (using 0.2-mm-pore polyethersulphone membranes for 4.5 bars) followed by $24-\mathrm{h}$ lyophilisation at $<-50^{\circ} \mathrm{C}$ vacuum. The infusion was shown by HPLC analysis to have $237 \mathrm{mg}$ of polyphenols per gram of extract (85.9\% quinic acid derivatives; $4.35 \%$ flavonols, 2.24\% hydroxycinnamic acid derivatives and 7.51\% unknown) (Cittadini et al, 2018).

\section{Experimental conditions}


Cittadini et al. Phenolic effects on brain

This study was carried out according to ethical and technical guidelines (approval by the Institutional Committee for the Care and Use of Laboratory Animals: UNC-FCM-SECYTCICUAL-2014-09-02, with authors adhering to the ARRIVE guidelines). Animals ( $\sim 23 \mathrm{~g})$ were bred under standard laboratory conditions with ad libitum commercial diet $(200 \pm 13 \mathrm{~g} / \mathrm{Kg} / \mathrm{day}$; Cargill SACI, Argentina) and potable water $(150 \pm 10 \mathrm{~mL} / \mathrm{Kg} /$ day; Aguas Cordobesas SA, Argentina). Two-month-old male BALB/cJ mice (The Jackson Laboratory) received $1.4 \times 10^{6}$ LAC-1 cells/animal by subcutaneous inoculation, which caused a lung adenocarcinoma to develop, and they were divided into three experimental groups $(n \geq 9)$ : Control received water, IP50 were treated with $50 \mathrm{mg} / \mathrm{Kg} /$ day of water-dissolved IP extract, and IP100 were treated with $100 \mathrm{mg} / \mathrm{Kg} /$ day of water-dissolved IP extract. A toxicity assay was previously tested to determine the safety of the dose (Cittadini et al, 2018). Animals were treated by oral intake for three weeks, with the assay being started on the same inoculation day. After treatment, the mice were sacrificed, and the organs were removed and weighed. The brain regions (telencephalon and diencephalon), liver and tumour were kept for experiments. In addition, a telencephalon fraction was separated and preserved for histological analysis. All tissues were mechanically homogenised with Milli-Q water and conserved to $-80^{\circ} \mathrm{C}$ until undergoing biochemical analysis.

\section{Analysis of phenolic compounds}

Analytical grade phenolic standards: chlorogenic, gallic, caffeic, ferulic and coumaric acids, quercetin and $\beta$-glucuronidase/sulphatase enzymes were acquired from Sigma-Aldrich Química SA (Madrid, Spain). HPLC-grade solvents were used (formic acid, methanol, ethanol and acetic acid), which were supplied by Prolabo (Madrid, Spain). Lyophilised samples of telencephalon, diencephalon, liver and tumour were homogenised with phosphate buffered saline (PBS) by using a IKA T-18 Basic Ultra Turrax Homogenizer, and then centrifuged at $1000 \mathrm{~g}$ for 10 min with an 
Cittadini et al. Phenolic effects on brain

Eppendorf 5415r centrifuge and analysed to determine their polyphenol profiles after $\beta$ glucuronidase/sulphatase treatment. Homogenates $(200 \mu \mathrm{L})$ were mixed with $0.58 \mathrm{~N}$ acetic acid $(20 \mu \mathrm{L})$ to prevent degradation, which were then analysed.

Samples were hydrolysed with $14 \mu \mathrm{L}$ of $\beta$-glucuronidase/sulphatase enzyme at $37^{\circ} \mathrm{C}$ for $30 \mathrm{~min}$, with methanol $(1 \mathrm{~mL})$ being added to complete the reaction. After this, samples were centrifuged for $10 \mathrm{~min}$, and solvents were evaporated using a SpeedVac concentrator at room temperature (30 min). Finally, samples were reconstituted with $0.20 \mathrm{~mL}$ Milli-Q water: ethanol $(1: 1, \mathrm{v} / \mathrm{v})$, mixed on a vortex, passed through a $0.45 \mu \mathrm{MPVDF}$ filter (polyvinylidene-difluoride) and analysed by HPLC-UV. The standards and supernatants $(20 \mu \mathrm{L})$ obtained were analysed using an Agilent 1200 Series liquid chromatograph with a quaternary pump, a photodiode array detector (DAD) and an Ultrabase C18 column $(5 \mu \mathrm{m} ; 4.6 \mathrm{~mm}$ x $150 \mathrm{~mm})$, which was set thermostatically at $25^{\circ} \mathrm{C}$. Solvents used for the analysis were formic acid $0.1 \%$ (A); HPLC-grade acetonitrile with $0.1 \%$ of formic acid (B); ultra-pure water (C) and acetonitrile (D) at a flow rate of $1 \mathrm{~mL} / \mathrm{min}$. The elution program was started with $90 \% \mathrm{~A}$ to $10 \% \mathrm{~B}$, and the gradient was the following: from $70 \% \mathrm{~A}$ to $30 \% \mathrm{~B}$ in $30 \mathrm{~min}$, from $65 \% \mathrm{~A}$ to $35 \% \mathrm{~B}$ in $35 \mathrm{~min}$, from $55 \% \mathrm{~A}$ to $45 \% \mathrm{~B}$ in $40 \mathrm{~min}$, and then returning to the initial conditions in $50 \mathrm{~min}$ (Hidalgo et al, 2010). Standards were analysed at different UV wavelengths (260, 280, 306 and $320 \mathrm{~nm})$, and their retention time (Rt) was recorded with DAD after HPLC separation. Quantification of the pure compounds ferulic, coumaric, and caffeic acids was performed at $320 \mathrm{~nm}$, while this was carried out for gallic and chlorogenic acids at $280 \mathrm{~nm}$. Quercetin was also observed at $320 \mathrm{~nm}$. The HPLC peaks of the phenolic compounds in the tissues were identified by comparing their retention times and UV absorption spectra with those of pure standards injected under the same conditions (Supplementary material 1).

The tissue phenolic content was measured at $750 \mathrm{~nm}$, which depended on the reducing capacity, by incubating $25 \mu \mathrm{L}$ of supernatants with the $2 \mathrm{~N}$ Folin reactant $(25 \mu \mathrm{L})$, water $(150 \mu \mathrm{L})$ and a 
Cittadini et al. Phenolic effects on brain

saturated sodium bicarbonate solution $(50 \mu \mathrm{L})$ for $30 \mathrm{~min}$ in darkness at $37^{\circ} \mathrm{C}$. The results were calculated as $\mu \mathrm{g} / \mathrm{g}$ of tissue using a standard curve of gallic acid, and expressed with respect to control (Albrecht et al, 2017; Cittadini et al, 2015).

Redox bioactivity of these compounds was assessed in each organ by the Spearman's correlation between phenolic concentrations and the lipoperoxide level determined as previously done (Cittadini et al, 2015).

\section{Determination of interleukin 6 (IL-6)}

The IL-6 levels were determined by ELISA using an OptEIA ${ }^{\mathrm{TM}}$ kit (BD Biosciences, USA) with absorbance at $450 \mathrm{~nm}$. IL-6 was measured in the encephalic regions (telencephalon and diencephalon). IL-6 concentrations were calculated from a standard curve (15.6-1000 pg/mL) and expressed per g of tissue (A-Jin et al, 2015).

\section{Histological analysis}

Telencephalon treated with IP and control group samples was fixed in buffered paraformaldehyde for $2 \mathrm{~h}$ at room temperature and processed for histological analysis. Then, telencephalon histological sections were stained by Hoechst to locate apoptotic cells. After rehydrating the cuts with decreasing concentrations of ethanol: water (50:50), Hoechst staining was prepared in PBS ( $1 \mathrm{~mL}$ PBS $+0.5 \mathrm{~mL}$ of Hoechst), and incubation was carried out for $10 \mathrm{~min}$ at $37^{\circ} \mathrm{C}$ in darkness. Following three washes with PBS, staining was performed with eosin $(1 \mathrm{~mL} \mathrm{PBS}+50 \mu \mathrm{L}$ of eosin), and sections were incubated again for $5 \mathrm{~min}$ at $37^{\circ} \mathrm{C}$ in darkness. Finally, washing with PBS was repeated. Three slides were observed for each treatment, and the percentage of apoptotic cells was recorded at 400x magnification using a Leica videomicroscope with epifluorescence (E: $350 \mathrm{~nm} / \mathrm{M}: 460 \mathrm{~nm}$ ). Images were analysed by Image J 1.48 software ${ }^{\circledR}$ 
Cittadini et al. Phenolic effects on brain

(USA). Also, fixed brains were stained with the classical hematoxylin/eosin technique and with the Kluver Barrera's staining (cresyl violet/luxol fast blue) to evaluate tissue and cytological changes.

\section{Statistical analysis}

Data were expressed as mean \pm standard error (SE) from at least three separate experiments performed twice. ANOVA models were used to evaluate differences between treatments, after which, the Fisher test was performed for mean comparison $(\mathrm{p}<0.05)$. The Spearman correlation was considered relevant for coefficients $>50 \%$. Analyses were performed using the InfoStat 2012 software (InfoStat Group, Argentina).

\section{Results}

\section{Phenolic compounds and activity}

The phenolic compounds identified by HPLC-UV were chlorogenic acid and quercetin, which were found at 7.17 and $29.28 \mathrm{~min}$, respectively (Figures 1, Table 1). Other phenolic compounds, such as gallic, coumaric, caffeic and ferulic acids, were not included as only trace values were detected. Low concentrations of quercetin were also verified by HPLC-MS (Supplementary material 1).

The IP50 treatment resulted in a significant increase of chlorogenic acid in telencephalon, diencephalon, and tumour, whereas quercetin was not detected. After the IP100 treatment, this acid increased even more in telencephalon, diencephalon, tumour, and liver $(\mathrm{p}<0.05)$, and the levels of quercetin rose in the diencephalon, and liver. No detectable compounds were found in the untreated control group (Table 1). 
Cittadini et al. Phenolic effects on brain

LAC-1-bearing mice showed increasing IP dose-dependent concentrations of both compounds at the studied sites, where the chlorogenic concentration was higher than the quercetin concentration. Also, chlorogenic acid exhibited a differential tissue distribution with an increased concentration principally in the telencephalon, but also in the diencephalon, liver, and tumour, while quercetin was mainly distributed in the diencephalon (Table 1).

Increasing concentrations of chlorogenic acid, but not quercetin, in the brain were positively correlated to the tissue phenolic content found in the same organ, which was enhanced 1.23-1.47 times in telencephalon, and 1.83-2.02 times in diencephalon after the IP50 and IP100 treatments, respectively.

No significant Spearman's correlations between bioavailable phenolic concentrations and the lipoperoxide level were found $(\mathrm{p}>0.1)$.

\section{IL-6 concentration}

IL-6 decreased after IP50 treatment in telencephalon (30\%), whereas it increased after IP100 $(23 \%)$ with respect to control $(\mathrm{p}<0.05)$. In diencephalon, both IP50 and IP100 resulted in a decreased IL-6 concentration with respect to control ( $9 \%$ and $29 \%$, respectively, $\mathrm{p}<0.05)$, with a dose-dependent response being revealed (Figure 2). Moreover, the IL-6 levels in diencephalon were negatively correlated to the chlorogenic and quercetin concentrations, whereas this outcome was not found in telencephalon. Diencephalon also exhibited a higher IL-6 concentration than telencephalon under the three treatments.

\section{Histology}

Several microscopic fields of brain grey matter were evaluated at 400x magnification. A growing number of cells were found in mice treated with IP50 and IP100 with respect to control $(\mathrm{p}<0.05)$. 
Cittadini et al. Phenolic effects on brain

Furthermore, mice under both treatments, but mainly IP100, presented better neuronal cytological characteristics in their brains (Figure 3, Supplementary material 2). These findings were associated with fewer apoptotic cells $(C=29 \%$, IP50=27\%, and IP100 $=18 \%$, characterised by condensed nuclei in Hoechst-stained brains, and lower pyknosis (Supplementary material 2). Neurons showed improvement of cresyl violet staining and cytology by increasing IP doses (Figure 3: rectangle), whereas cellular retraction (Figure 3: oval) and gliosis foci (preliminary data not shown) were found without treatment.

\section{Discussion}

The extract of Ilex paraguariensis (IP) supplied two phenolic compounds: chlorogenic acid and quercetin, which were identified in an oral IP dose-dependent manner at different organic sites of LAC-1-bearing mice after intake. In agreement with the present study, pharmacological research has established that both compounds are metabolised in a highly inducible way, which explains their low permanence in the liver. They are also able to cross the blood-brain barrier to reach the brain (Andrade and Assuncao 2012; Manach et al, 2005). Related to this, several molecules that are bioactive in vitro are less effective in vivo, because they cannot cross this boundary (De Oliveira et al, 2017). Another important factor is that brain regions can exhibit differential selectivity in order to obtain phenolic compounds from the bloodstream (El Mohsen et al, 2002). Chlorogenic acid was constantly found by HPLC-UV in treated mice, in accordance with its high concentration in this extract, whereas the rest of phenolic acids (gallic, ferulic, caffeic, and coumaric acids) were inconstantely found in trace levels. On the other hand, the flavonoid quercetin found in lower concentrations was additionally confirmed by mass spectroscopy (Supplementary material 1), which is an original result in murine brain after oral supply of a phytoextract. 
Cittadini et al. Phenolic effects on brain

IP is a good candidate as an oral phenolic source, because its polyphenols are available after digestion, thus enhancing intestinal absorption (Albrecht et al, 2017). The levels of chlorogenic acid and quercetin found in the brain can be related to kinetic properties (e.g. accomplishment of the Lipinski's rules), tissue affinity, and the biochemical stability of the cerebrospinal fluid and the encephalic microenvironment, which is highly regulated by the blood-brain barrier and glia (De Oliveira et al, 2017; Kumar et al, 2018). Chlorogenic acid was the major compound found after IP intake, in agreement with previous studies that reported its high concentration and predominance in Ilex paraguariensis (Cittadini et al, 2018; Albrecht et al, 2017). Furthermore, this phenolic acid was also observed at the tumours for both IP doses, which may be advantageous given its cancer modulating potential (Yamagata et al, 2018). Therefore, the correlation observed in telencephalon and diencephalon between chlorogenic and phenolic concentrations was espectable. Although unpublished data of our group suggest variable redox effects in different organs of LAC-1-bearing mice, the current work did not show redox involvement of the identified bioavailable compounds as lipoperoxide-modulating agents. The antioxidant capacity of IP has demonstrated to be neuroprotective under different conditions (Colpo et al, 2017; De Lima et al, 2017). In the case of lung cancer, additional deleterious responses are triggered in the brain and its cells, such as inflammation (Cittadini et al, 2018; unpublished data), which was controlled here.

The IP-related IL-6 reduction is consistent with the antiinflammatory activity of its phenolic compounds (Cittadini et al, 2018). It is known that diencephalic functions are crucial for organic integration and depend on many factors, such as nutrition, immunity, and neurotransmission (Schreiner et al, 2017), with phenolic compounds being able to regulate these leading to beneficial local and systemic responses (Miranda et al, 2107). Previous data have reported effects of IP derivatives on LAC-1-bearing mice against neuroinflammation, demyelination, and 
Cittadini et al. Phenolic effects on brain

cachexia (Cittadini and Repossi, 2016). Here, telencephalon revealed lower levels of IL-6 with a biphasic response (a decrease in the case of IP50, and an increase for IP100), which reflects the complex neurophysiological role and regulation of this cytokine. In addition, IL-6 participates in the response of mature neurons and glial cells in both normal and pathological conditions involving neurotrophin-like and neuroimmune modulating mechanisms (Erta et al, 2012). The different responses in diencephalon and telencephalon to IP are due to the CNS spatial heterogeneity (structure, function, and cellular composition). This confers a great complexity and multiple mechanisms with a predilection of xenobiotics in certain biochemical systems (Maurer and Philbert, 2015). In fact, diencephalon also incorporated quercetin, an antiinflammatory molecule (Ishisaka et al, 2011), which enhanced IL-6 reduction after IP100. In addition, glia and neurons respond differently to foreign molecules at different doses (Kapoor et al, 2006).

LAC-1 induces neurodegeneration in mice (Kapoor et al, 2006), whereas neuroprotective effects with an improvement in the cell count and morphology were found in the present study in brains treated with IP. In this sense, lung cancer can damage nervous tissue and induce cell death during its evolution (Giglio and Gilbert, 2010), whereas polyphenols have a protective potential (Silva and Pogacnik, 2017), with chlorogenic acid antiapoptotic activity also having been reported (Anggreani and Lee, 2017). Moreover, this IP-promoted neuroprotection agrees with other results already discussed, and with results found in another neuropathological model (De Lima et al, 2018).

In summary, our results showed that orally administered Ilex paraguariensis extract led to a dosedependent brain accumulation of chlorogenic acid and quercetin in lung adenocarcinoma-bearing mice, where they exerted different neuroprotective effects on the telencephalon and diencephalon, to alleviate cancer-related neurological complications. 
Cittadini et al. Phenolic effects on brain

\title{
Acknowledgments
}

The revision of the manuscript by Paul Hobson $\mathrm{PhD}$, native speaker, is appreciated.

\section{Funding}

Financial support: SECYT - Universidad Nacional de Córdoba (grant $n^{\circ}$ 313/2016), INYM and CONICET (grant $n^{\circ}$ 4342/2016 22320160100044CO), Argentina; Ministerio de Economía, Industria y Competitividad (I+D+I Retos Program grant AGL2016-76832-R), Spain.

\section{Conflict of interest statement}

On behalf of all authors, the corresponding author states that there is no conflict of interest.

\section{References}

A-Jin, L., Kyung-Jin, C., Jae-Hong, K. (2015) MyD88-BLT2-dependent cascade contributes to LPS-induced interleukin-6 production in mouse macrophage. Experimental \& Molecular Medicine, 47:e156.

\begin{abstract}
Albrecht, C., Cittadini, M.C., Canalis, A.M., Guzman, M.L., Olivera, M.E., Soria, E.A. (2017) Bioavailability of phenolic compounds and redox state of murine liver and kidney as sexdependent responses to phytoextracts. Revista de Facultad de Ciencias Médicas de Universidad Nacional de Córdoba, 74, 338-44.

Andrade, J.P., Assuncao, M. (2012) Protective effects of chronic green tea consumption on agerelated neurodegeneration. Current Pharmaceutical Design, 18, 4-14.

Anggreani, E., Lee, C.Y. (2017) Neuroprotective effect of chlorogenic acids against Alzheimer's disease. International Journal of Food Sciences and Nutrition, 6(1), 330-7.

Bracesco, N., Sanchez, A.G., Contreras, V., Menini, T., Gugliucci, A. (2011) Recent advances on Ilex paraguariensis research: minireview. Journal of Ethnopharmacology, 136(3), 378-84.
\end{abstract}


Cittadini et al. Phenolic effects on brain

Cittadini, M.C., Canalis, A.M., Albrecht, C., Soria, E.A. (2015) Effects of oral phytoextract intake on phenolic concentration and redox homeostasis in murine encephalic regions. Nutritional Neuroscience, 18(7), 316-22.

Cittadini, M.C., García-Estévez, I., Escribano-Bailón, M.T., Rivas-Gonzalo, J.C., Valentich, M.A., Repossi, G., Soria, E.A. (2018) Modulating activity of phenolic compounds from American plant infusions on fatty acid-related interleukin-6 release in glial cells. Nutrition and Cancer, 70(2), 267-77.

Cittadini, M.C., Repossi, G. (2016). Modulating effect of the yerba mate (Ilex paraguariensis) consumption on the neurological compromise produced by lung cancer in mice [Spanish]. In Informes finales cuarta cohorte de becarios: Becas de formación inicial en investigación en cáncer 2014-2015, INC. Ministerio de Salud: Buenos Aires; 84-92.

Colpo, A.C., De Lima, M.E., Maya-López, M., Rosa, H., Márquez-Curiel, C., Galván-Arzatec, S., Santamaría, A., Folmer, V. (2017) Compounds from Ilex paraguariensis extracts confer antioxidant effects in the brains of rats subjected to chronic immobilization stress. Applied Physiology, Nutrition, and Metabolism. 42(11), 1172-1178.

De Lima, M.E., Colpo, A.C., Maya-López, A.C.,Rosa, H., Túnez, I., Galván-Arzate, S., Santamaría, A.,Folmer, V. (2017) Protective effect of Yerba mate (Ilex paraguariensis St. Hill.) against oxidative damage in vitro in rat brain synaptosomal/mitochondrial P2 fractions. Journal of Functional Foods. 7, 447-452.

De Lima, M.E., Colpo, A.C., Rosa, H., Fernandes Salgueiroa, A.C., Pires da Silva, M., Noronha, D.S., Santamaría, A., Folmera, V. (2018) Ilex paraguariensis extracts reduce blood glucose, peripheral neuropathy and oxidative damage in male mice exposed to streptozotocin. Journal of Functional Foods. 44, 9-16. 
Cittadini et al. Phenolic effects on brain

De Oliveira, D.M., Sampaio, G.R., Pinto, C.B., Catharino, R.R., Bastos, D.H. (2017) Bioavailability of chlorogenic acids in rats after acute ingestion of maté tea (Ilex paraguariensis) or 5-caffeoylquinic acid. European Journal of Nutrition, 56(8), 2541-56.

El Mohsen, M.M.A., Kuhnle, G., Rechner, A.R., Schroeter, H., Rose, S., Jenner, P., Rice-Evans, C.A. (2002) Uptake and metabolism of epicatechin and its access to the brain after oral ingestion. Free Radical and Biology Medicine, 33(12), 1693-702.

Erta, M., Quintana, A., Hidalgo, J. (2012) Interleukin-6, a major cytokine in the Central Nervous System. International Journal of Biological Sciences, 8(9), 1254-1266.

Giglio, P., Gilbert, M.R. (2010) Neurologic complications of cancer and its treatment. Current Oncology Report, 12(1), 50-59.

Hidalgo, M., Sánchez-Moreno, C., de Pascual-Teresa, S. (2010) Flavonoid-flavonoid interaction and its effect on their antioxidant activity. Food Chemistry, 121(3), 691-96.

Ishisaka, A., Ichikawa, S., Sakakibara, H., Piskula, M.K., Nakamura, T., Kato, Y., Ito, M., Miyamoto, K., Tsuji, A., Kawai, Y., Terao, J. (2011) Accumulation of orally administered quercetin in brain tissue and its antioxidative effects in rats. Free Radical and Biology Medicine, 51(7), 1329-36.

Islami, F., Torre, L.A., Jemal, A. (2015) Global trends of lung cancer mortality and smoking prevalence. Translational Lung Cancer Research, 4(4), 327-38.

Jurado Gámez, B., García De Lucas, M.D., Gudín Rodríguez, M. (2001) Lung cancer and paraneoplastic syndromes [Spanish]. Anales de Medicina Interna (Madrid), 18(8), 440-46.

Kapoor, N., Pant, A.B., Dhawan, A., Dwievedi, U.N., Seth, P.K., Parmar, D. (2006) Cytochrome P450 1A isoenzymes in brain cells: Expression and inducibility in cultured rat brain neuronal and glial cells. Life Sciences, 79(25), 2387-94. 
Cittadini et al. Phenolic effects on brain

Koike, H., Sobue, G. Paraneoplastic neuropathy (2013). Handbook Clinical Neurology, 115, 71326.

Kumar, G., Paliwal, P., Mukherjee, S., Patnaik, N., Krishnamurthy, S., Patnaik, R. (2018) Pharmacokinetics and brain penetration study of chlorogenic acid in rats. Xenobiotica, 21, 1-7. Yamagata, K., Izawa, Y., Onodera, D., Tagami, M. (2018) Chlorogenic acid regulates apoptosis and stem cell marker-related gene expression in A549 human lung cancer cells. Molecular and Cellular Biochemistry, 441(1-2), 9-19.

Manach, C., Williamson, G., Morand, C., Scalbert, A., Rémésy, C. (2005) Bioavailability and bioefficacy of polyphenols in humans. I. Review of 97 bioavailability studies. American Journal of Clinical Nutrition, 81(S), 230-42.

Maurer, L.L., Philbert, M.A. (2015) The mechanisms of neurotoxicity and the selective vulnerability of nervous system sites. Handbook Clinical Neurology, 131, 61-70.

Miranda, A.R., Cittadini, M.C., Albrecht, C., Soria, E.A. (2017) Regional oxidative stress in encephalon of female mice with polyphenolic exposure from tea extracts in oral overweight plant-based treatment. Revista de Facultad de Ciencias Médicas de Universidad Nacional de Córdoba, 74, 197-202.

Orosz L. (2018). Effect of the Ilex paraguariensis (yerba mate) consumption on the breast milk biochemical composition of women from Cordoba (Argentina) [Spanish]. MD Thesis, Universidad Nacional de Córdoba, Córdoba, Argentina.

Piegari, M., Soria, E.A., Eynard, A.R., Valentich, M.A. (2017) Delay of Lung Adenocarcinoma (LAC-1) development in mice by dietary oleic acid. Nutrition and Cancer. 69(7), 1069-74.

Sateia, H.F., Choi, Y., Stewart, R.W., Peairs, K.S. (2017) Screening for lung cancer. Seminars in Oncology, 44(1), 74-82. 
Cittadini et al. Phenolic effects on brain

Schreiner, F., Ackermann, M., Michalik, M., Hucklenbruch-Rother, E., Bilkei-Gorzo, A., Racz, I., Bindila, L., Lutz, B., Dötsch, J., Zimmer, A., Woelfle, J. (2017) Developmental programming of somatic growth, behavior and endocannabinoid metabolism by variation of early postnatal nutrition in a cross-fostering mouse model. PLoS One, 12(8), e 0182754.

Silva, R.F.M., Pogačnik, L. (2017) Food, polyphenols and neuroprotection. Neural Regeneration Research, 12(4), 582-3. 
Cittadini et al. Phenolic effects on brain

Table 1. Phenolic compounds in LAC-1-bearing male BALB/cJ mice $(\mu \mathrm{g} / \mathrm{mg}$ of dry tissue: mean $\pm \mathrm{SE})$ after three-week treatment

\begin{tabular}{|c|c|c|}
\hline & $\begin{array}{l}\text { Chlorogenic acid } \\
\text { (280 nm HPLC-UV) }\end{array}$ & $\begin{array}{l}\text { Quercetin } \\
(320 \mathrm{~nm} \text { HPLC-UV) }\end{array}$ \\
\hline \multicolumn{3}{|c|}{ Telencephalon } \\
\hline Control & $\mathrm{Nd}$ & $\mathrm{Nd}$ \\
\hline IP50 & $0.22 \pm 0.11^{*}$ & $\mathrm{Nd}$ \\
\hline IP100 & $1.01 \pm 0.15^{*}$ & $\mathrm{Nd}$ \\
\hline \multicolumn{3}{|c|}{ Diencephalon } \\
\hline Control & $\mathrm{Nd}$ & $\mathrm{Nd}$ \\
\hline IP50 & $0.07 \pm 0.00 *$ & $\mathrm{Nd}$ \\
\hline IP100 & $0.24 \pm 0.00 *$ & $0.02 \pm 0.00 *$ \\
\hline \multicolumn{3}{|c|}{ Liver } \\
\hline Control & $\mathrm{Nd}$ & $\mathrm{Nd}$ \\
\hline IP50 & $\mathrm{Nd}$ & $\mathrm{Nd}$ \\
\hline IP100 & $0.09 \pm 0.05$ & $0.01 \pm 0.01$ \\
\hline \multicolumn{3}{|c|}{ Tumour } \\
\hline Control & $\mathrm{Nd}$ & $\mathrm{Nd}$ \\
\hline IP50 & $0.05 \pm 0.02$ & $\mathrm{Nd}$ \\
\hline IP100 & $0.20 \pm 0.03 *$ & $\mathrm{Nd}$ \\
\hline \multicolumn{3}{|c|}{$\begin{array}{l}\text { Oral treatments with Ilex paraguariensis (IP) extract: IP50: } 50 \\
\mathrm{mg} / \mathrm{Kg} / \text { day, or IP100: } 100 \mathrm{mg} / \mathrm{kg} / \text { day. }\end{array}$} \\
\hline
\end{tabular}



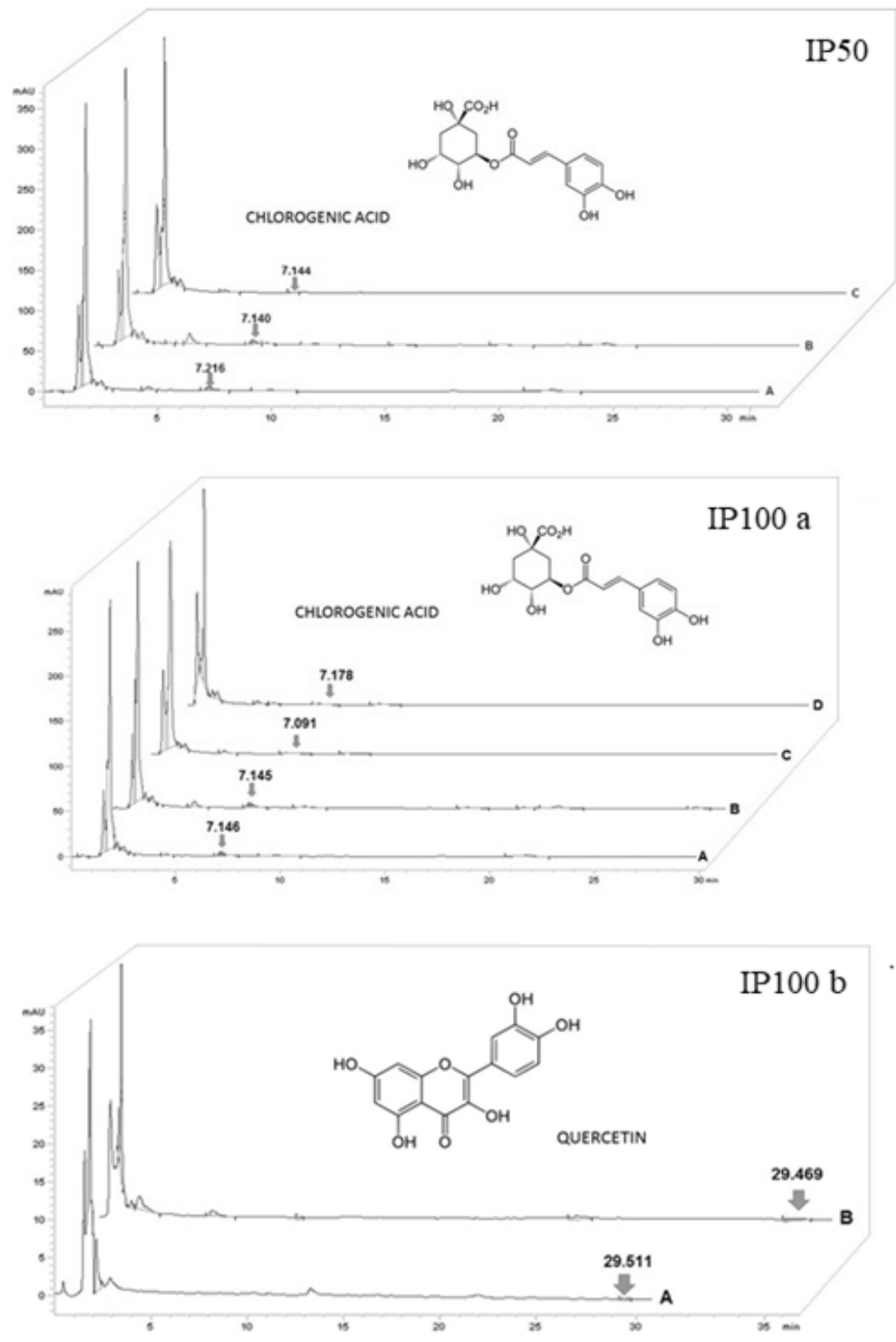

Chlorogenic acid (Rt $\approx 7.17 \mathrm{~min}, 280 \mathrm{~nm}$ HPLC-UV) in telencephalon $(A)$, diencephalon (B), tumour (C) and liver (D) of lung adenocarcinoma-bearing male BALB/c] mice treated orally for 3 weeks with $100 \mathrm{mg} / \mathrm{Kg} / \mathrm{day}$ of Ilex paraguariensis extract (IP100 a) or $50 \mathrm{mg} / \mathrm{Kg} /$ day (IP50), and Quercetin (Rt $\approx 29.28 \mathrm{~min}, 320 \mathrm{~nm}$ HPLC-UV) in diencephalon (A) and liver (B) (IP100 b).

$129 \times 200 \mathrm{~mm}(96 \times 96$ DPI $)$ 


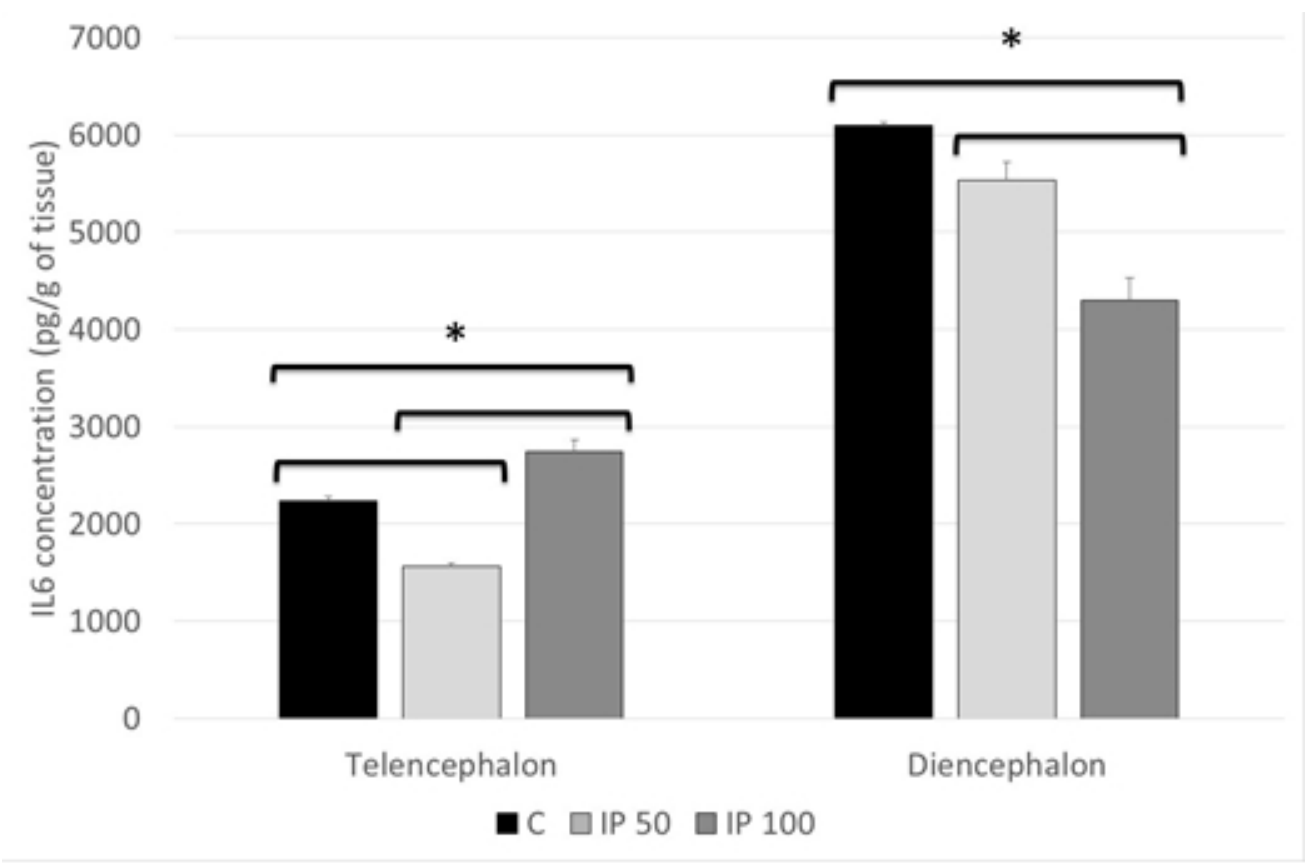

Tissue interleukin 6 (IL-6) concentration (mean \pm SE) in telencephalon and diencephalon of lung adenocarcinoma-bearing male BALB/c] mice treated orally for 3 weeks with $100 \mathrm{mg} / \mathrm{Kg} / \mathrm{day}$ of Ilex paraguariensis extract (IP100), $50 \mathrm{mg} / \mathrm{Kg} /$ day (IP50), or $0 \mathrm{mg} / \mathrm{Kg} / \mathrm{day}$ (C: untreated control). * Significant differences at $\mathrm{p}<0.05$. 
Grey matter cells of lung adenocarcinoma-bearing male BALB/c] mice treated orally for 3 weeks with 100 $\mathrm{mg} / \mathrm{Kg} /$ day of Ilex paraguariensis extract (IP100), $50 \mathrm{mg} / \mathrm{Kg} /$ day (IP50), or $0 \mathrm{mg} / \mathrm{Kg} /$ day (C: untreated control). Representative microphotographs with histological stainings at 400x magnification. * Significant differences at $p<0.05$ (mean $\pm S E$, quantified using Fiji Image] $v 1.51$ software).

\section{$254 \times 190 \mathrm{~mm}(96 \times 96 \mathrm{DPI})$}
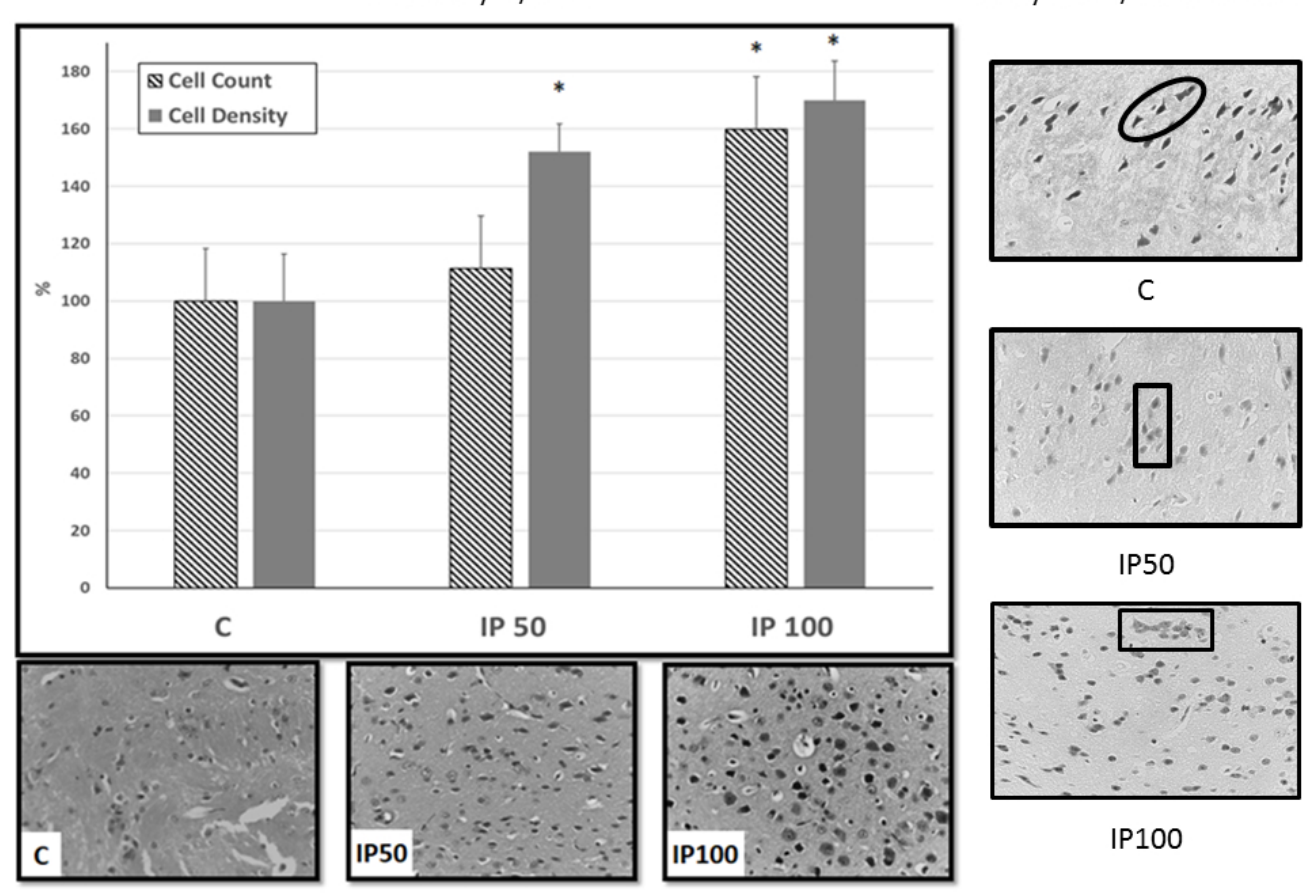

C

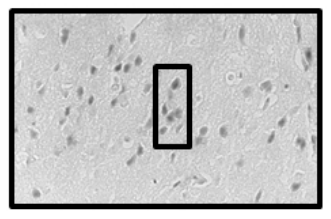

IP50

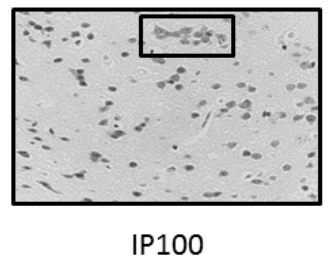

